\title{
Dynamic Performance Improvement of Doubly Fed Induction Motor Based on Hybrid Computational Technique and Variable Structure Control
}

\author{
Mohamed Yazid Zidani ${ }^{(1)^{*}}$, Noureddine Brakta ${ }^{(2)}$, Omar Bendjeghaba ${ }^{(3)}$ \\ (1) Department of Electrical EngineeringUniversity of Mostefa Ben Boulaïd Batna2; Batna, Algeria \\ (2),(3) Department of Eelctrical Engineering LREEI, Faculty of Hydrocarbons \& Chemestry University \\ of Boumerdes, Boumerdes, Algeria \\ zidanikarim212@yahoo.fr
}

\begin{abstract}
In this paper, we present The sliding mode control (SMC) methodology based on the theory of variable structure systems that has been widely used for robust control of nonlinear systems. Nevertheless, this type of control has an essential inconvenience, which is the chattering phenomenon caused by the discontinuous control part. In order to reduce the effects of the chattering phenomenon, second order sliding mode (SOSM) seems to be a very attractive solution. To eliminate the remains of chattering phenomenon, a new control scheme based on fuzzy second order sliding mode control (FSOSMC) is proposed in this paper. This fuzzy second order sliding mode controller is destined to the speed control of doubly fed induction motor (DFIM) which is based on the decoupling control to enhance robustness under different operating conditions such as load torque and in the presence of parameters variation.

The simulation results for various scenarios show the performances of the proposed control in terms of, precision, rapidity and stability for the high powers DFIM operating at variable speeds.
\end{abstract}

Keywords: DFIM, Decoupling Control, SOSMC, FSOSMC.

\section{INTRODUCTION}

The introduction section must contain theory related to the paper topic along with state of art study and well referenced citations. Make this section as informative as possible to justify the work and situate it with respect to the literature.

The doubly fed induction motor (DFIM) with wounded rotor have become increasingly used in industry. This type of motor has been neglected by researchers for several years because of its disadvantages. However, it has come back to the forefront because of the progression of the control techniques and the accessibility to its rotor [1-17].

The operation of a variable speed motor needs some control techniques in order to obtain a high performance system. Among the control techniques currently applied to asynchronous machines, we can find scalar control, vector control, direct torque control and nonlinear control. Indeed, the scalar control is the first that has been introduced in the industry. However, this control does not satisfy the most efficient applications. This has opened the way for researchers to search for new control techniques that meet industrial requirements.
The vector control presents the evolution of the scalar control [2] and it can be performed by two basic methods: direct vector control (DVC) and indirect vector control (IVC). These ensures control of the flux and the electromagnetic torque at the same time [3]. The most widely used control method is the proportional integral $(\mathrm{PI})$ and the proportional integral derivative (PID) control. These later are easy to design and implement, but it has difficulty in dealing with parameter variations and load disturbances [4]. These controllers are designed using a linear control technique ensuring local stability in a vicinity of the operation point.

Recently, the SMC methodology has been widely used for robust control of nonlinear systems [9]. Based on the theory of variable structure systems, SMC has attracted a lot of research on control systems for the last two decades. Nevertheless, this type of control has an essential inconvenience, which is the chattering phenomenon caused by the discontinuous control part. In order to reduce the effects of the chattering phenomenon, second order sliding mode seems to be a very attractive solution [16]. This method generalizes the essential sliding mode idea by acting on the higher order time derivatives 
of the sliding manifold, instead of influencing the first time derivative as it is the case in SMC, therefore reducing chattering and avoiding strong mechanical efforts while preserving SMC advantages [13]. Indeed, this method has proven in several studies and research applications its effectiveness in minimizing this undesirable phenomenon which is mainly due to the presence of a discontinuous control term containing the sign function. So this fact has led other researchers to find a new methods of control. These efforts have been rewarded by the introduction of modern control techniques such as artificial intelligence. The latter adapts better to these requirements and robust. In this work, we will focus on solving the remains of chattering phenomenon problems by using the fuzzy logic technique that is part of artificial intelligence.

To eliminate the remains of chattering phenomenon, a new control scheme based on fuzzy second order sliding mode control is proposed in this paper. The fuzzy secondorder sliding mode approach have been actively developed over the last two decades for chattering attenuation and robust control of uncertain systems with relative degree two and higher, respectively [7- 8- 9-10-11].

In this work, all the presented simulations are carried out on two power supplies and a doubly fed induction motor (DFIM). The stator and the rotor are powered through two electronic inverters. The latter is driven by a direct vector controller (DVC) using pulse width modulation PWM and rotor flux orientation strategy. Several simulations have been done using the MATLAB/Simulink software in order to validate the theoretical results.

The remainder of this paper is structured as follows: in section 2, the machine model with a decoupling control of DFIM is presented. In section 3 , speed controllers synthesis are presented. The simulation results of FSOSMC, SOSMC and the $\mathrm{PI}$ controller are shown in section 4 . Finally, the conclusions are presented in section 5 .

\section{MATHEMATIC MODELS OF DFIM AND STRUCTURE OF THE DECOUPLING CONTROL}

The main objective of the vector control of doubly fed induction motors is to control the torque and the flux independently; this is done by using a $\mathrm{d}$-q rotating reference frame synchronously with the rotor flux space vector as shown in the figure 1. The general full order dynamic model of DFIM is given by:

$$
\begin{gathered}
V_{S d}=R_{S} I_{S d}+\frac{d \phi_{S d}}{d t}-\omega_{S} \phi_{S q} \\
V_{S q}=R_{S} I_{S q}+\frac{d \phi_{S q}}{d t}+\omega_{S} \phi_{S d} \\
V_{R d}=R_{R} I_{R d}+\frac{d \phi_{R d}}{d t}-\omega_{R} \phi_{R q} \\
V_{R q}=R_{R} I_{R q}+\frac{d \phi_{R q}}{d t}+\omega_{R} \phi_{R d}
\end{gathered}
$$

The electromagnetic torque of a threephase doubly fed induction machine modeled in the Park reference is given by the following relation:

$$
C_{e m}=\frac{3 p M}{2 L_{R}}\left(\phi_{R d} I_{S q}-\phi_{R q} I_{S d}\right)
$$

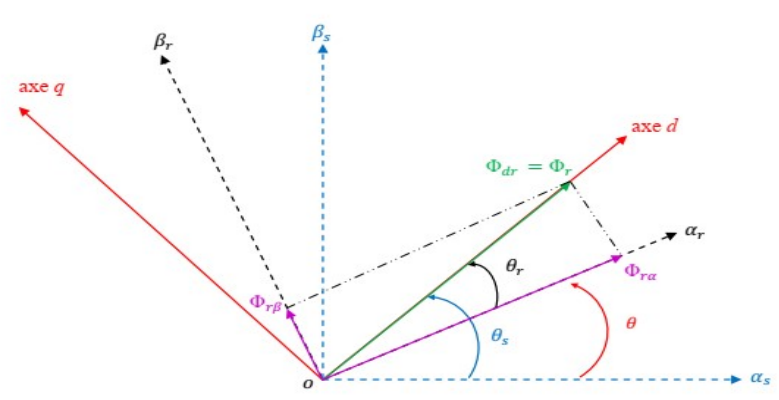

Fig.1. Rotor field orientation on the d-axis

Then, after the d-axis is aligned with therotor flux vector, we get:

$$
\begin{aligned}
& \varphi_{R}=\varphi_{R d}, \varphi_{R q}=0 ; \\
& I_{R q}=-\frac{M_{S R}}{L_{R}} I_{S q}, I_{R d}=0 ;
\end{aligned}
$$

\section{Control of currents and compensation terms}

It can be seen that the voltage equations (1),(2),(3) and (4) include terms of coupling between $d$-axis and q-axis. These terms are considered as disturbances and are cancelled by using a decoupling method [5]. In order to obtain a decoupling between $d$ and $\mathrm{q}$ axis we have used a method which was introduced by D. LECOQ [6]. It requires the use of four current correctors; let us define new voltages as:

$$
\begin{aligned}
& \frac{I_{s q}(S)}{V_{t s q c}(S)}=\frac{I_{s d}(S)}{V_{t s d c}(S)}=\frac{1}{R_{s}+\sigma L_{s} S} \\
& \frac{I_{R q}(S)}{V_{t R q c}(S)}=\frac{I_{R d}(S)}{V_{t R d c}(S)}=\frac{1}{R_{R}+\sigma L_{R} S}
\end{aligned}
$$




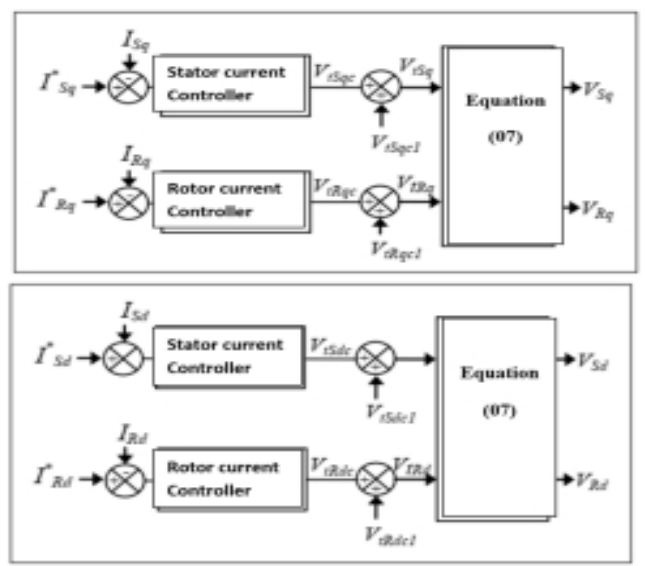

Fig.2. Decoupling and regulation of the currents The current references are given by:

$$
\begin{aligned}
I_{s d}^{*} & =\frac{L_{R}}{M_{s R}} \phi_{R d}^{*} \\
I_{s q}^{*} & =\frac{L_{R}}{P M_{S R} \phi_{R d}^{*}} C_{e m}^{*} \\
I_{R d}^{*} & =0 \\
I_{R q}^{*} & =-\frac{1}{P \phi_{R d}} C_{e m}^{*}
\end{aligned}
$$

Thus, figure 2 shows the control structure of the currents.

\section{SPEED CONTROLLERS SYNTHESIS}

\section{Speed control via Second order sliding mode controller :}

The sliding mode technique is developed from variable structure control to adjust feedback by previously defining a surface. The system which is controlled will be forced to that surface, then the behavior of the system slides to the desired equilibrium point [14]. When the system is in sliding mode, the system behavior is not affected by any modeling uncertainties and/or disturbances. The design of the control system will be demonstrated for a nonlinear system presented in the canonical form [15-20]:

$\dot{x}=f(x, t)+B(x, t) V(x, t), x \in R^{n}, V \in R^{m}, \operatorname{ran}(x, t)=m(8)$

With control in the sliding mode, the goal is to keep the system motion on the manifold $\mathrm{S}$, which is defined as:

$$
\begin{array}{r}
S=\{\xi: \varepsilon(\xi, \tau)=0\} \\
e=x^{*}-x
\end{array}
$$

The sliding mode surface in our study is the error between the measured and reference speed, so we can write the following expression:

$$
S=\Omega^{*}-\Omega
$$

The first order derivate of (11), gives:

$$
\begin{gathered}
\dot{S}=\dot{\Omega}^{*}-\dot{\Omega} \\
J \frac{d \Omega}{d t}=K_{e m} I_{R q}-f \Omega-C_{r}
\end{gathered}
$$

Substituting the expression of equation (13) in equation(12), we obtain:

$$
\dot{S}=\dot{\Omega}^{*}-\frac{K_{e m}}{J} I_{R q}-\frac{f}{J} \Omega-\frac{C_{r}}{J}
$$

$\mathrm{I}_{\mathrm{Rq}}$ will be the component of the control vector used to constraint the system to converge to $S=0$. The control vector $U_{e q}$ is obtain by imposing so the equivalent control components are given by the following relation:

$$
U_{e q}=-\frac{f}{K_{e m}} \Omega+\frac{J}{K_{e m}} \dot{\ominus}^{*}-\frac{C_{r}}{K_{e m}}
$$

To obtain good performances, dynamic and commutation around the surface, the control vector is imposed as follows [12]:

$$
U=U_{e q}+U_{s w}
$$

Where $U_{e q}, U_{s w}$ are the equivalent control and the switching control, respectively and the switching input, $U_{s w}$ is introduced as :

$$
U_{s w}=K_{s} \operatorname{sign}(s)
$$

where $K_{s}$ is a positive constant, $K_{s} \in R^{+}$, and $\operatorname{sgn}($.$) denotes signum function defined$ as [19]:

$$
\operatorname{sign}(s)=\left\{\begin{array}{rc}
1, & S>0 \\
0, & S=0 \\
-1, & S<0
\end{array}\right.
$$

The sliding mode will exist only if the following condition is met:

$$
S . \dot{S}<0
$$


In order to reduce the effects of chattering phenomenon and to ensure the DFIM's speed convergence to their reference second order sliding mode seems to be a very attractive solution [13]. Considering the sliding mode surface given by (12), the following expression can be written:

$$
\left\{\begin{array}{l}
\dot{S}=\dot{\Omega}^{*}-\frac{K_{e m}}{J} I_{R q}-\frac{f}{J} \Omega-\frac{C_{r}}{J} \\
\ddot{S}=Y(t, x)+\Lambda(t, x) I_{R q}
\end{array}\right.
$$

Where $\mathrm{f}(\mathrm{x}, \mathrm{t})$ and $\Lambda(\mathrm{x}, \mathrm{t})$ are uncertain functions which satisfy:

$Y>0,|Y|>\lambda ; 0<K_{m}<\Lambda<K_{M}$

Basing on the super twisting algorithm introduced by Levant in [18], the proposed high order sliding mode controller contains two parts [15]:

$$
I_{R q}=v_{1}+v_{2}
$$

With

$$
\begin{aligned}
& \dot{v_{1}}=-K \operatorname{sign}(S) \\
& \dot{v_{2}}=-l|S|^{\gamma} \cdot \operatorname{sign}(S)
\end{aligned}
$$

In order to ensure the convergence of the sliding manifolds to zero in finite time, the gains can be chosen as follows [15].

$$
\begin{aligned}
& I_{R q}=v_{1}+v_{2} \\
& k>\frac{\lambda}{K_{m}} \\
& I^{2} \geq \frac{4 \lambda}{K_{m}^{2}} \frac{K_{M}(k+\gamma)}{K_{m}(k-\lambda)} \\
& 0<\gamma \leq 0.5
\end{aligned}
$$

Let us consider the internal schema of the SOSM regulator in Fig. 3.

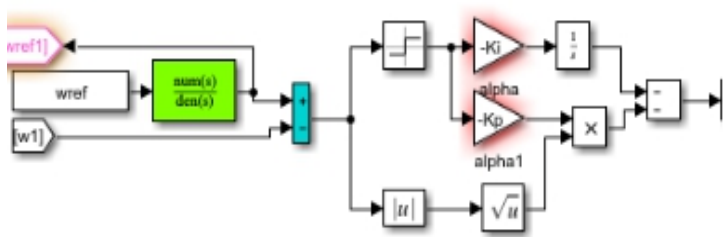

Fig.3. Internal structure of the SOSM speed controller

\section{Speed control via Fuzzy second order sliding mode controller:}

The fuzzy second order sliding mode command (FSOSMC) is similar to a classical SOSMC technique. However, the switching regulators term $\operatorname{sign}(S(x))$, has been replaced by $F L$ regulators.

Let us consider the internal schema of the FSOSM regulator in Fig. 4.

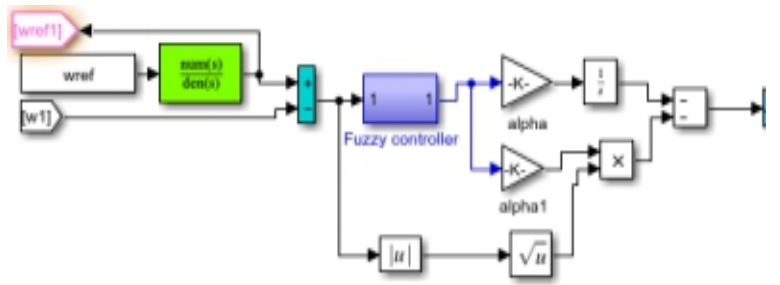

Fig. 4 Internal structure of the FSOSM speed controller

The principle diagram of direct vector control (CVD) with rotor flux oriented on the d-q axis is shown in the figure 5 .

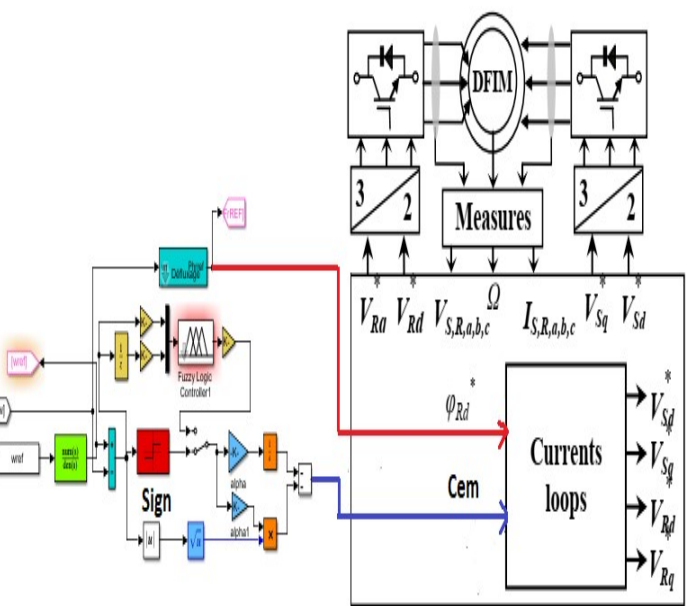

Fig.5. Block diagram of the proposed control scheme of the DFIM

\section{SIMULATION RESULTS}

In order to test the robustness of the regulation, two tests are carried out. Firstly a change in the speed set point from (150rd/s), $(-150 \mathrm{rd} / \mathrm{s})$ to $(30 \mathrm{rad} / \mathrm{s})$ with a cyclic change of different load torque levels was applied to the DFIM by time. Secondly the rotor resistance is increased up to $50 \%$ of its nominal value. The results of this simulation is shown in Fig. 6.

The speed variation is represented by Figs. 6. And it contain zooms on moments of constraint changes. We note that the fuzzy second order sliding mode controller based drive system can handle the sudden change in load torque without ripples, undershoot, overshoot and a negligible steady state error. 
However The SOSM controller presents ripples but without a steady state error, undershoots and overshoots. The PI controller presents a steady state error, undershoots and overshoots. Thus the PI regulator is not perfectly robust with respect to the variation of the load.

It can be seen that the variation in the rotor resistance does not cause any undesirable effect on all the dynamic responses of the fuzzy second order sliding mode controller. However the SOSM and PI controllers has a disturbance during the variation in the rotor resistance. Therefore, this shows the robustness of the FSOSMC controller in the face of the variation of the rotor resistance.

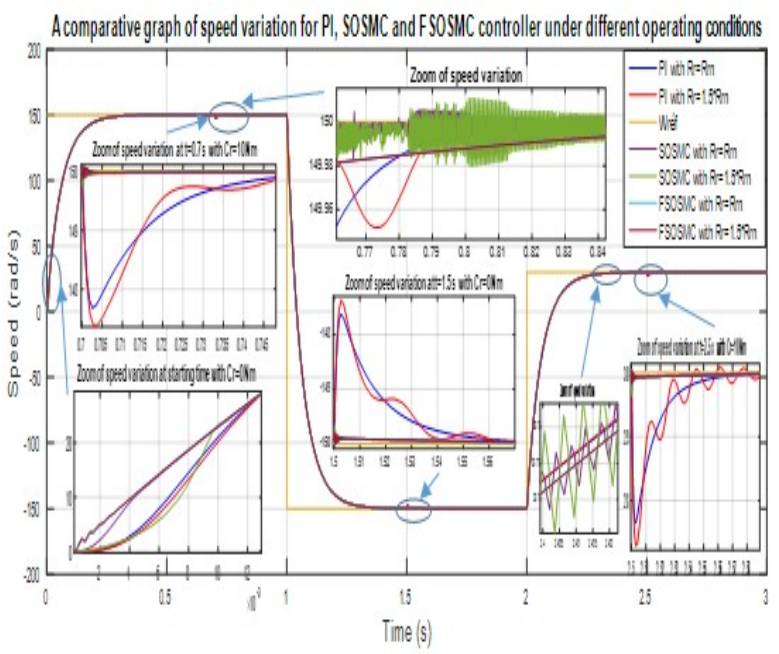

Fig. 6. Simulation results of speed variation

\section{CONCLUSION}

In this paper, we have proposed a new robust control method based on hybrid computational technique and variable structure technique destined to the speed control of doubly fed induction motor (DFIM) with a direct rotor flux orientation control. The results obtained with this hybrid technique are very interesting compared to the conventional controller especially in eliminating of the chattering phenomenon. The FSOSMC regulator proves robustness against rotor resistance variation and insensitivity to load torque disturbance as well as faster dynamics with negligible steady state error at all dynamic operating conditions. As the result, the proposed FSOSMC has very satisfactory tracking performance than those tuned by the SOSM and PI controller.

\section{Nomenclature}

\begin{tabular}{|c|l|}
\hline Parameter & \multicolumn{1}{|c|}{ Description } \\
\hline $\boldsymbol{V}_{\boldsymbol{s}}$ & Stator Voltage component \\
$\boldsymbol{V}_{\boldsymbol{R}}$ & Rotor Voltage component \\
$\boldsymbol{I}_{\boldsymbol{s}}$ & Stator current component \\
$\boldsymbol{I}_{\boldsymbol{R}}$ & Rotor current component \\
$\boldsymbol{\Phi}_{\mathrm{dqSR}}$ & Stator/Rotor flux in $d-q$ frame \\
$\mathbf{d}-\mathbf{q}$ & Reference frame \\
$\mathbf{R}_{\mathbf{s}}$ & Stator resistance \\
$\mathbf{R}_{\mathbf{R}}$ & Rotor resistance \\
$\mathbf{L}_{\mathbf{s}}$ & Stator inductance \\
$\mathbf{L}_{\mathbf{R}}$ & Rotor inductance \\
$\mathbf{C}_{\mathrm{em}}$ & Electromagnetic Torque \\
$\mathbf{C}_{\mathbf{r}}$ & Load Torque \\
$\mathbf{K}_{\mathrm{em}}$ & Torque coefficient \\
$\boldsymbol{P}$ & Number of pole pairs \\
$\boldsymbol{J}$ & Moment of inertia \\
$\boldsymbol{f}$ & Viscous coefficient \\
$\mathbf{M}$ & Mutual inductance \\
$\mathbf{\Omega}$ & Mechanical speed \\
$\boldsymbol{\omega}$ & Electrical speed \\
$\boldsymbol{\theta}$ & Angular position \\
$\boldsymbol{\sigma}$ & Blondel dispersion coefficient \\
\hline
\end{tabular}

\section{References}

[1] L. Youb, A. Crăciunescu, “ Etude comparative entre la commande vectorielle à flux orienté et la commande directe du couple de la machine asynchrone ", P.B. Sci. Bull, Series C, Vol. 69, No. 2, 2007, pp.113-128.

[2] S N. Sivanandam, S. Sumathi , S. N. Deepa ," Introduction to Fuzzy Logic using Matlab", Springer-Verlag Berlin Heidelberg 2007

[3] I. Salgado , O. Camacho , C. Yáñez , I. Chairez, "Proportional derivative fuzzy control supplied with second order sliding mode differentiation Engineering Applications of Artificial Intelligence", vol. 35 , October 2014, pp. 84-94

[4] L. Zadeh, Fuzzy sets. Inf. Syst. 8, 1965, pp. 338-353.

[5] K.Jarray , M.Laakam, L.Sbita, "Robust speed control for stator flux oriented controlled induction motor drive», CD- JTEA, 21-22, Hammamet, (Tunisie), Mai 2004.

[6] R.D. Lorenz, D.B. Lawson, "A Simplified Approach to Continuous On-Line Tuning of Field-Oriented Induction Machine Drives", IEEE Trans. Ind Appl, vol. 26, Issue.3,mayJune 1990.

[7] M. Mihoub, A.S. Nouri, R.R Abdennour, " Real-time application of discrete second order slidingmode control to a chemical reactor", Control Eng. Pract. 17, 1089-1095 (2009)

[8] I. Boiko, L. Fridman, R. Iriarte, A. Pisano, E. Usai, "Parameter tuning of second-order sliding mode controllers for linear plants with dynamic actuators", Automatica 42, 833-839 (2006)

[9] L. Nezli, O. Zouaid,"Sliding mode control of a five-phase series-connected two-motor drive", Algerian Journal of Signals and Systems, Vol.1. $N^{\circ}$. 1. pp 59-68. june 2016

[10] G. Bartolini, A. Farrara, E. Usai, "Applications of sub-optimal discontinuous control algorithm 
for uncertain second order systems", Int. J. Robust Nonlinear Control 7, 299-319 (1997)

[11] J. Davila, L. Fridman, A. Levant, "Secondorder sliding mode observer for mechanical systems", IEEE Trans. Autom. Control 50, 1785-1789 (2005)

[12] A. Dahdouh, S. Barkat, A. Chouder, "A combined Sliding mode space vector modulation control of the shunt active power filter using robust harmonic extraction method", Algerian Journal of Signals and Systems. Vol 1, $\mathrm{N}^{\circ} 1$. pp 37-46. june 2016

[13] A. Levant, "Higher-order sliding modes, differentiation and output feedback control," Int J Control, vol. 76, pp. 924-941, 2003.

[14] R. J. Wai and J. M. Chang, "Implementation of robust wavelet-neural-network slidingmode control for induction servo motor drive," In: IEEE Trans. On Industrial Electronics, vol. 50, no. 6, pp. 1317-1334, December 2003.

[15] T. Sun, Z. Chen and F. Blaabjerg, "Flicker study on variable speed wind turbines with doubly fed induction generators," In: IEEE Transactions on Energy Conversion, pp. 896905, December 2005.

[16] A. Levant, L. Alelishvili, "Integral high-order sliding modes," IEEE T Automat Contr, vol. 52, pp. 1278-1282, 2007.

[17] M.Y. Zidani, L. Youb, S. Belkacem, F. Naceri , " Design of robust control using fuzzy logic controller for doubly fed-induction motor drives",U.P.B.Sci. Bull., Vol. 81, 1.2019, pp.159-170.

[18] A. Levant and L. Alelishvili, "Integral highorder sliding modes," IEEE Trans. Autom. Control, vol. 52 , no. 7 , pp. 1278-1282, July 2007.

[19] I. Eker, "Second-order sliding mode control with experimental application," elsevier ISA Transactions, 49, pp. 394-405, 21 April 2010.

[20] F. Inel, Y. Zennir, "Robust Sliding mode control for novel type of parallel robot " Algerian Journal of Signals and Systems, vol. $2 \mathrm{~N}^{\circ}$ 4. pp 218-227. December 2017. 